\title{
Cultural Influence on Comparative Research: The Need for Cultural Equivalence of Scales
}

\author{
Gustavo Almeida \\ Permanent Professor of the Postgraduate Program in Administration - PPGAd / UFF, Brazil. \\ WebURL: http://ppgad.sites.uff.br/gustavo-de-oliveira-almeida/
}

\begin{abstract}
Management models evolved from classical models to current models, and were enhanced with psychological, social and cultural components. However, currently many management theories are still applied without considering the cultural context. The aim of this paper is to analyze the limitations and applicability of theoretical models and scientific knowledge in different cultural contexts from which they were designed. To this end, an investigation was made on the literature on international management, assessing issues such as origin of publication, number of articles and authors cited. With respect to the theoretical framework, it included studies on culture and cultural research on comparative studies (cross-cultural) and measurement equivalence. In terms of methodology, this study is presents as a theoretical essay. The limitations of the use of scales in contexts different than where they were created are discussed, especially concerning comparison between groups. Finally, we discuss possible solutions and the next steps for future research.
\end{abstract}

KEYWORDS: Culture. Comparative Studies. Scale Equivalence. Research Methods.

\section{Introduction}

The management of people, materials and financial assets has existed since the earliest times of mankind. His own family unit requires a certain Division of labour, which involves necessarily the management. Classically, it is considered that the study of Administration begins in a structured manner from the works of Taylor and Fayol thereafter, with the investigation of time and movement for greater organizational efficiency and functions of the administrator (plan, organize, command, coordinate and control) (MORGAN, 1989)

These theories created in the industrial context, particularly in the United States, were absorbed relatively quickly in other sectors and countries, which have completely different contexts. The techniques and procedures of scientific management were considered the best way to organize companies, in order to achieve efficiency and effectiveness of processes. The individual, then, seemed fully mapped and predictable about their motivations, expectations and behavior patterns (MORGAN, 1989).

However, this model of the classical Administration received criticism from other schools of thought that have drawn attention to the human dimension of relations in the organization. From this perspective, these studies sought to decrease the reductionism of homo economics, passing to consider social and psychological variables inherent in the organizational environment. Later schools warned to the influence of the external environment in the operation of the company and thus, theories such as the open systems approach (MORGAN, 1989). 
Although the organizational studies have advanced and produced more sophisticated models, there's still a hegemony of theories designed in American or Western context. Many researches consider these models are completely exportable and usable in any cultural context. Thus, concepts are imported into other realities in the absence of a process of adaptation to the local context and validation of assumptions.

Vernon (1964) was one of the first American scholars to test the validity of theories of the Organization in other cultural contexts, to identify which environmental factors would have influence in the management of the company. This first approach is known as the first International management paradigm. The second paradigm emphasizes the challenges of companies operate in two or more distinct cultural contexts. Accordingly, we sought to understand the limitations and practical applications in different contexts from which they were designed.

A key milestone of these studies was the work of Hofstede (1980), which revealed the importance of the cultural dimension in management theories and questioned more directly the role of American models as universalist theories culture generators free (HOFSTEDE, 1980). Soon after the initial research of Hofstede, several authors have called attention to the problems in disregard cultural values that Nations, groups and even businesses. However, it is still very common to use ' uncritical ' American theories without considering whether they are applicable to other contexts (JACK et al., 2008; WESTWOOD; JACK, 2000).

One of the main roles of the paradigm of international management is just understand how the theory and practice of management can be applied in wider contexts, keeping the proportions and specific characteristics of different cultures (CONTRACTOR, 2000; MARTINEZ; TOYNE, 2000). However, this true internationalization of research has not been achieved, because some countries, groups and lines of research have dominated the generation of knowledge, actually restricting the objection process, critical to the advancement of scientific knowledge (WESTWOOD; JACK, 2007).

In this context, the post-colonial approach intends to just question the generalization of theories, methods and findings. According to Westwood and Jack (2007), this concentration is not only geographical, but also political, intellectual, and institutional, serving only a limited set of subjects, methods and interests. Even when the peripheral countries are involved in such research, they do as "guinea pigs" of theories, where the interests are not from subject, but from the researcher, dominant (WESTWOOD; JACK, 2007).

On the above, this article has as main objective to analyze the limitations and the possibility of application of theoretical models and scientific knowledge in the area of international management in different cultural contexts from which they were designed. To this end, a review of the literature studies on culture (HOFSTEDE contemplating, 2001; TROMPENAARS, 1993), comparative cultural research (cross-cultural) and adaptation of scales (MARTINEZ; TOYNE, 2000; HUI; TRIANDIS, 1985; MARTIN; FISCHER, 2010).

The article exposes the need for more rigorous statistical testing, including factor analysis multi-group, to determine whether the scores of groups can be compared, are similar scales and has the same sense for groups, as primordial condition for valid research achievements that seek to compare not only different cultures, but also groups. Regarding your relevance, the search is justified to expand the studies about the influence of the ' culture ' in the development of scientific research. Finally, this study draws attention to the limitations arising from the predominance of theories and methodologies from some countries for the advancement of knowledge, since concepts are universal and absolute, that is, the same suffering of influences local culture.

\section{Theoretical framework}

\subsection{Definitions of culture}

http://dx.doi.org/10.19085/journal.sijmas050401 
One of the first definitions of culture was conceived by Tylor, in your work Primitive Culture, 1871. Tylor sought to demonstrate that culture can be the object of systematic studies, because it would be a natural phenomenon that has causes and patterns, allowing an objective study and analysis that can generate laws about the cultural process. Thus, the culture would be a compound that includes knowledge, beliefs, morals, laws, customs and other habits acquired by man as a member of society. (HILAL, 2001).

Convergent with that notion, Good enough (1996) defines culture as a set of beliefs or standards, shared by a group of people who help individuals to define something, how to feel, what to do and how to do it. Linton (1945) presents culture as being the setting and the result of learned behavior that is passed by the members of a society from generation to generation. Finally, Rokeach (1973) culture as a system of values and norms shared by a group of people, that would be a kind of map to guide your life. This value system is based on a set of principles to assist the individual in choosing alternatives and in decision making.

Punnett (1998) draws attention to the importance of understanding the relationship between cultural and economic/social issues, demonstrating a number of culture-related features. The author also believes that culture is not innate, but rather that people are introduced to it during your training, learning their rules and regulations. Such an approach implies that people can participate in other cultures, learning and internalizing their rules and habits (PUNNETT, 1998; HOFSTEDE, 2001).

The culture expresses the values and the beliefs that the members of this group share. These values are manifested through symbols, such as myths, stories, legends, and a specialized language, guiding individuals of a referred to culture in the way we think, Act and make decisions. The culture also causes people to differentiate themselves by their cultural elaborations, inventions and different resolutions of problems (HILAL, 2001).

There are some factors, practices and values that exist in all civilizations, but they vary in the way they are perceived or recovered in the most diverse people. Thus, there are elements that could serve as a common denominator among people as different, as for example, the Division of labour, education, faith, folklore, games, language, laws, population policy, among other factors. (HILAL, 2001). The various concepts exposed in understanding of different perspectives given the ' culture '. The way each culture treats these items shows a value judgment, expressing the basic values and beliefs of each locale.

Given the great subjectivity and the diversity of factors linked to culture, there are few models that seek to understand deeply the variable "culture". Some works have been developed in order to measure the culture from some quantitative dimensions and compare them. The number of frameworks to understand national cultures is still relatively small, due to the difficulty in conducting studies with sufficient scale to analyze and compare cultures of various countries.

One of the most cited on culture is the Hofstede (1991). The author proposes that culture is a composite of elements that can be classified into four categories: basic values, symbols, rituals and heroes. The values serve as instruments for racionalizarmos our decisions, and the deeper level of underlying values, which determines the meaning of their practices. The values are based on the beliefs and mental "programming" of individuals, being acquired in socialization processes. The values themselves are not observable, but the behaviors that they support and bestow legitimacy.

The very laws of countries are based on values and other cultural practices accepted, and therefore a way to clarify the expected values of behavior and conduct. This approach of culture believes that such categories are present and built in the collective and not individual level, being this way, something different from the personality of each subject. In a study conducted at IBM, Hofstede (1980) found four dimensions to the national cultures: hierarchical distance, individualism-collectivism, masculinity-femininity and control of uncertainty. These dimensions 
allow you to sort the countries in different relative positions. It should be noted that the combination of the values of the countries in relation to each of these dimensions allows a better understanding of the culture being studied.

In this research, between IBM employees with similar jobs in different countries, assign each country an index relative to your level of hierarchical distance. In countries where the hierarchical distance is low, the dependency of subordinates concerning its managers is limited. The hierarchical distance can thus be defined as the degree of acceptance by those who have less power in the institutions of a country, of unequal distribution of power.

The way every society and considers that should be ties between the individual and the rest of society can be represented by the dimensions ' individualism ' and ' collectivism '. In societies where the ties between individuals are not strong and each must take care of yourself and your only immediate family is called individualistic society. Already in a society where people are more integrated into highly cohesive groups and have a relationship of loyalty, is known as collectivist society (HOFSTEDE, 1991).

Already the size of control of uncertainty measures the degree of anxiety of the inhabitants of a country in relation to unknown or uncertain situations, being directly related to the need for rules and laws, and may be written or not in order to decrease the number of situations where there aren't sure about something. The control of uncertainty is linked to anxiety about something that might happen and also the acceptance of ambiguity about the unknown or new situations (HOFSTEDE, 1991).

Finally, the size of masculinity-femininity indicates a particular culture's preference for male or female values, associated with the roles that these genres have historically in society. These so-called traditional roles dictate that men should be linked to activities outside the home: hunting and war in the traditional societies and the equivalent, in economic terms, in our modern societies. In short, men should be strong and competitive. On the other hand, women should take care of the home and children (HOFSTEDE, 1991).

Trompenaars (1993) presents yet another important contribution to research on culture. The author identified five cultural dimensions in which relationships with people can be defined: universalism versus particularism, collectivism vs. individualism, neutral vs. emotional, diffuse versus specific and achievement versus assignment. These five values guidelines significantly influence the ways in which we negotiate and manage, as well as our responses to the moral dilemmas.

The dimension of "universalism versus particularism" specifically addresses relationships and rules and of the importance that is given by a particular culture to each of these factors. Universalism and particularism rules values emphasizes relationships. To explain the dimension "collectivism versus individualism", Trompenaars (1993) describes the individualism as being oriented towards the goals themselves and collectivism as being oriented towards the common goals.

The dimension "neutral vs. emotional or affective" deals with the role played by reason and emotion in interpersonal relationships, i.e., with the preferences for styles of verbal communication and nonverbal communication. The dominant dimension would set if people are emotionally neutral or are more affective. Members of the neutral oriented cultures tend not to show your feelings and keep them carefully controlled. On the other hand, in cultures with affective orientation, people clearly demonstrate their feelings through variety of gestures (TROMPENAARS, 1993).

With respect to the dimension "diffuse versus specific", Trompenaars (1993) believes that people can engage in specific activities of life separately or so diffuse, in multiple areas of life at the same time. In cultures with specific guidance, managers tend to act as managers only at work 
and not in other environments of their lives, as, in the local club. In cultures with diffuse orientation, the Director tends to assume that role at all times and expects to be treated as such inside and outside the organization.

The dimension "attitude in relation to time" is related to the importance of different cultures give the past, present and future. Trompenaars (1993) attentive to the fact that the vision that people have time to be sequential, that is, a series of events which succeed one another, where the past, present and future are interrelated, so that ideas about the future and memories of the past influence actions of this.

The dimension "conquest versus role" deals with how the status is assigned in a given society. In some societies, the status is based on achievements, while in others, relies on features, such as age and gender. Consequently, in conquest-oriented cultures, the status is based on the individual makes while on assignment-oriented cultures, the status is based on who the individual is (TROMPENAARS, 1993).

These dimensions shape the structure and organization of the cultures and the very laws of countries are made based on values and other cultural practices. When companies internationalize, there's an almost inevitable movement toward universalist forms of thought. (TROMPENAARS, 1993).

\section{Research Methodology}

According to Marczyk et al. (2005), science can be defined as a systematic and methodological approach to the generation of new knowledge. Instead of merely casual remarks and the use of informal ways to see the world, the scientists seek to generate new knowledge through careful observations about reality, using systematic approaches, controlled and methodical, being possible, in this way, generate valid and reliable conclusions on the subject studied (MARCZYK et al., 2005).

Lincoln and Guba (2000) indicate four ways to understand empirical realities or paradigms that reflect different philosophical positions: positivism, post positivism, critical theory, and Constructivism. Constructivism relativizes the issues, arguing that the reality is socially constructed and that search results are created with hermenêuticos and dialectical methods. Already the reality of critical theory is historically determined, i.e., the methods and knowledge are subjective and related cultural values.

The positivist position, for your time, indicates that reality exists and can be objectively known. The dominant paradigm in areas such as psychology is the approaches, which assumes that our knowledge about the reality is imperfect, but that the degree of imperfection can be differentiated through systematic experimentation, based on the principle of refutability (LINCOLN; GUBA, 2000).

In this perspective, it is understood that this article has post-positivist research approaches, since it recognizes and points out the difficulties and limitations when performing cross cultural comparisons and imperfection in the measurement of the variables investigated. In addition, a postcolonial approach was used, as it seeks a new assessment of the area and of knowledge and was questioned the generalization of theories, methods and findings (WESTWOOD; JACK, 2007).

In addition to this classification, the present study has qualitative and descriptive nature, as has been reviewed publications on culture and management. The qualitative study is appropriate when you want to understand the phenomenon in depth, considering the context in which it occurs (GODOY, 1995). With the support of related literature, a discussion on the impacts of using ' uncritical ' dominant theories and methods, without considering the cultural differences that exist. 
This research also is configured as a theoretical article. According to Severino (2002), a theoretical article it is a well-developed study, formal, conclusive and discursive, consisting of logic and reflective display with emphasis in argumentation, interpretation and personal judgment.

\section{Cross Cultural Research}

The application of comparative cultural research (cross-cultural) is widely used in studies of international management (MARTINEZ; TOYNE, 2000). The cross-cultural studies are surveys conducted with members of various cultures that have diverse experiences, which generate predictable and significant differences in behavior. The cross-cultural psychology is defined by Berry et al. (2002, p. 3) as "the study of similarities and differences in the functioning of individuals in various cultural and ethno-cultural groups, relations between psychological, sociocultural variables, ecological, biological, and changes in these variables.

The cross-cultural research uses data from multiple people in order to test hypotheses about human behavior. Frieflmeier et al. (2005) complements the cross-cultural researches are carried out with the objective of describing universal phenomena or cultural differences and to explain differences through general aspects. So the searches can be differentiated according to your objective to investigate what is common and what is different.

Besides the possibility to perform comparisons between groups of different cultures, the use of cross-cultural studies presents as leverage to higher probability of variation of a given phenomenon, and may represent the difference between a useful study and a useless. This because, when using a single data region, there may not be enough variation, or even if there was, it can be focused on one side of the spectrum of the phenomenon and so the generated theory tends to be too specific to be useful (c. EMBER; M. EMBER, 2009).

There are several views regarding the influence of culture on the behavior and the possibility of conducting study or comparisons. These positions are typically divided into three broad, which differ in your approach to influence of culture, being called Absolutism, relativism and Universalism (BERRY et al., 2002).

In absolutist perspective, the culture does not have a significant role in human behavior or characteristics. The psychological phenomena would be basically the same regardless of the culture where they occur. With this in mind, there are no problems about cross cultural comparisons, and can be used the instruments already validated in a culture, requiring only a translation for the language where it will be used (if different), no concern with cultural influences (BERRY et al., 2002).

On the other hand, the relativist perspective assumes that all human behavior is influenced by the culture and human diversity explanations are based on the cultural context that these people have developed. In this vision, usually using the values and meanings given to each of the cultures studied phenomenon, avoiding any value judgment or evaluative character. Avoid describe, categorize or understand others from a point of view influenced by a foreign culture (BERRY et al., 2002).

The differences between cultures are assigned exclusively to the way that the concepts are understood by each of the cultures and these are interpreted qualitatively. For example, there would be no differences between levels of entrepreneurship across cultures, but that each context presents a way to undertake (m. EMBER; C. EMBER, 2009). Considering the assumptions of this approach, the comparative studies are avoided, because they are difficult methodological and conceptual point of view. Achieving these requires instruments developed specifically for each culture that the phenomenon will be studied (BERRY et al., 2002). 
Finally, the Universalist perspective can be considered a common point between the two other approaches, because it has the premise that the processes or behaviors are common to all mankind (absolutist perspective), but that these processes are influence of culture (relativistic perspective), being a matter of the degree of interference of the cultural variables on each behavior. (BERRY et al., 2002).

This approach performs comparisons between cultures carefully, with appropriate methodologies. His interpretations take into account the cultures and the phenomena, allowing comparisons between different cultures, at the same time noting the similarities that would be universal and specific differences attributed to culture. In table 3, adapted from Berry et al. (2002), a concise comparison was conducted between the three approaches discussed.

Table 3: three orientations in relation to comparative cross cultural

\begin{tabular}{|c|c|c|c|}
\hline Factors & Absolutist & Universalist & Relativist \\
\hline $\begin{array}{l}\text { Factors influencing } \\
\text { the behavior }\end{array}$ & Biological & $\begin{array}{l}\text { Cultural and } \\
\text { biological }\end{array}$ & Cultural \\
\hline $\begin{array}{l}\text { Role of culture to } \\
\text { explain the behavior }\end{array}$ & Limited & Substantial & Substantial \\
\hline Similarities due to & $\begin{array}{l}\text { Common basic } \\
\text { processes }\end{array}$ & $\begin{array}{l}\text { Common basic } \\
\text { processes }\end{array}$ & $\begin{array}{l}\text { Usually is not } \\
\text { searched }\end{array}$ \\
\hline Differences due to & $\begin{array}{l}\text { Differences between } \\
\text { species }\end{array}$ & $\begin{array}{l}\text { Interactions between } \\
\text { culture and other } \\
\text { factors }\end{array}$ & Cultural Influences \\
\hline Emics and Etics & Étic Imposed & Etic Derived & Emic \\
\hline $\begin{array}{l}\text { Definition of concepts } \\
\text { independent of } \\
\text { context }\end{array}$ & Directly available & Hard to get & Normally impossible \\
\hline $\begin{array}{l}\text { Measurement of } \\
\text { context-independent } \\
\text { concepts }\end{array}$ & Usually possible & Often impossible & Impossible \\
\hline $\begin{array}{l}\text { Procedures for } \\
\text { evaluation }\end{array}$ & $\begin{array}{l}\text { Standardized } \\
\text { Instruments }\end{array}$ & Adapted Instruments & Local Instruments \\
\hline Comparison & $\begin{array}{l}\text { Direct, frequent and } \\
\text { evaluative. }\end{array}$ & $\begin{array}{l}\text { Controlled, frequent } \\
\text { and not evaluative. }\end{array}$ & $\begin{array}{l}\text { Normally avoidable, } \\
\text { no evaluative }\end{array}$ \\
\hline
\end{tabular}

Source: adapted from BERRY et al., (2002)

So, these three dimensions have implications for the psychological concepts and to assess similarities and cross-cultural differences, mainly the issue of universality, which indicates ownership of a concept to be suitable for use in any culture or be invariant with respect to methods and crops (BERRY et al., 2002).

Van de Vijver and Poortinga (1982) indicate that there is a degree of variation in the data between cultural groups as a function of the similarity of cultural patterns or other factors between the groups, representing a continuum between the universality of concepts. Ranging from more 
universal concepts and other more specific, to differentiate between these positions on the concepts, the authors have established four levels of universality of concepts synthesized in table 4.

Table 4: levels of universality of concepts

\section{LEVEL OF UNIVERSALITY DEFINITION}

\section{UNIVERSAL CONCEPTS Has a high level of abstraction, which usually has nothing to do with measurement scale.}

WEAK UNIVERSAL

Concepts that the measures have already been validated in every culture studied.

STRONG UNIVERSAL

STRICT UNIVERSAL
Can be measured by the same metric in any culture.

Have the same distribution between scores in all cultures surveyed.

\section{Source: adapted from Van de Vijver and Poortinga (1982)}

The comparative researches are conducted not only by anthropologists, are currently held in various fields of knowledge, such as in the areas of biology, sociology, economics, business administration, psychology. With this, it is essential that the researcher, regardless of the area, consider that the cultural factor can influence the results of the study that is held in different contexts (c. EMBER; M. EMBER, 2009).

\subsection{Adaptation and the Cultural Equivalence of Scales}

One of the main methods for application of intercultural research is the cultural adaptation of scales. This procedure involves transforming a scale developed in a context to be used in a different locale, especially in countries with different languages. There are various methods for the realization of cultural adaptation and one of the most used methods involves five main stages, namely: (i) the initial translation, (ii) synthesis of the translations, (iii), (iv) retro review by a Committee of experts and finally, (v) the application pre-test of the sample on which the scale is being adapted (CRESWELL, 1998).

As to the validity of the new version of the scale, there are several types of verification of the validity that can be made in a cultural adaptation: validity, content validity, criterion validity and construct validity. In a cultural adaptation, you must test the reliability of the final version of the scale through the Alpha of Cronbach's alpha. Face validity and content will be made through the analysis of the Committee of experts and of the pre-test. The validity of the criteria may be held if there is another instrument that measure the same concept, comparing the result of the application of the two measures. These procedures, although they are used universally, are based on statistical models and criteria settings such as internal consistency (Alpha of Cronbach's alpha) and confirmatory factor analysis using equations structural (HAIR et al., 2005).

However, although the scale can be adapted, translated and translated, the concept may not be completely understood in another context or even present different meaning in a culture distinct from that was created. 
To check the possibility of comparison between different groups or cultures, should check the cultural equivalence of measures, usually through comparison of models using the technique of structural equation modeling (HUI; TRIANDIS, 1985; MARTIN; FISCHER, 2010).

Hui and Triandis (1985) indicate that to perform comparisons between constructs between different cultures a number of prerequisites must be present. The accuracy of the equivalence requirements grows as the desired comparison becomes more dependent on scales and common metrics. The initial requirement is the cross-cultural equivalence, which must be answered before any type of comparison involving cultures is held.

The conceptual equivalence means that the concepts studied in cultures must be repeated, i.e. to be conceptually equivalent. In the case of this research, the entrepreneurship is a worldwide phenomenon that presents a central idea in two countries studied, and also within the five Brazilian regions.

The equivalence in the operationalization of a construct represents the transition between the theory and the measurement of this construct, the construct is materialized and operated the same way, that is items are grouped using a same procedure, to keep the same meaning in the cultures studied.

Equivalence of items refers to measuring the same construct using the same instrument, i.e., each item should mean the same for crops being compared, if the items are not equivalent, does not measure the same construct and therefore the results cannot be compared.

Finally, Hui and Triandis (1985) indicate that there is equivalence scale, where other types of equivalence have been established and in addition, it can be shown that the construct have the same metric, i.e. the values obtained in the tests have the same meaning in the cultures studied. While this is the ideal type of equivalence, can hardly reach this level. But to perform comparisons between the scales, one should achieve the level of equivalence scale or metric.

Therefore, before you can examine variables and perform comparisons between the groups is essential to test the model of measurement invariance in different groups, to ensure that the structure and factorial loads are equivalent among the groups studied, or that the constructs compared the same latent construct measured in two or more groups compared.

There are basically two types of tests for model measurement invariance: configural and metric. Configural invariance allows testing of a way to test the first three types of equivalence for Hui and Triandis (1985), while the equivalence scale is tested by metric invariance. Both tests are conducted through a confirmatory factor analysis. The difference between the two tests is that on configural invariance, the groups being tested are divided and if checks to see if the model has a good fit to the data, without any restriction to the values of the parameters.

Analysis of metric invariance, performs the test by introducing a restriction that the value of the parameters between the two groups must be the same, and checking to see if there is a significant difference between the models, using comparison of statistics, as the Chi-square test (Hui and Triandis, 1985). The first test to establish the configural invariance is retained with the model test data from each of the groups tested. This test is the first step, and indicates whether the constructs has similar meanings in different groups, namely if the construct has the same meaning and structure, so the first test which allows the comparison between groups (MARTIN; FISCHER, 2010).

The second step of the configural invariance testing is typically performed using the multigroupfactor analysis approach (MARTIN; FISCHER, 2010). In this procedure all groups are included to check the fit of the data with all the samples, without applying any restriction of equality in terms of factorials loads and error covariance. According to Martin and Fischer (2010) 
the level of restriction varies, depending on the need of comparison between the groups, the different parameters that can be restricted, along with the invariance testing is available in Table 5:

Table 5: Models and types of metric invariance

\begin{tabular}{|c|l|l|}
\hline $\begin{array}{c}\text { Model } \\
\text { Comparison }\end{array}$ & Equality constraint Parameters & Type of invariance \\
\hline $\mathbf{0}$ model & No & (Configural Invariance) \\
\hline $\mathbf{1}$ model & Factorials loads & Weak invariance \\
\hline $\mathbf{2}$ model & Factorials and intercepts loads of items & Strong invariance \\
\hline $\mathbf{3}$ model & $\begin{array}{l}\text { Factorials, intercepts loads of items and variances } \\
\text { and covariances of the factors }\end{array}$ & $\begin{array}{l}\text { Metric invariance (equal } \\
\text { on the scales) }\end{array}$ \\
\hline $\mathbf{4}$ model & $\begin{array}{l}\text { Factorials loads, intercepts, variance and covariance } \\
\text { of the residual items (errors) }\end{array}$ & Strict Invariance \\
\hline
\end{tabular}

Source: adapted from MARTIN \& FISCHER (2010)

Martin and Fischer (2010) indicate that the kind of strict invariance, represented in the model 4 has no practical interest to compare average groups, also represents a too restrictive test to compare groups. So, are normally tested three types of invariance (loads factorials, intercepts and covariance between the factors).

If these tests are performed and obtain proper fit, infers that the groups tested feature factorial structure equal, equivalence and scale items, i.e. the scores obtained by the instrument can be validly compared, and differences eventually found are due to actual differences in the construct measured, and does not come from differences in the use of the scale.

\section{The need for cross cultural equivalency}

One of the greatest limitations exist to the achievement of cross-cultural studies is related to the concept of culture itself. The existing models present difficulties in measuring some differences, which turn out to be more complex than the five Hofstede dimensions or the six cultural dimensions of Trompenaars (BASKERVILLE, 2003). Although both authors acknowledge that the measurement of a national culture presents limitations, articles comparing other values that are not covered by these scales, proliferate every day in major journals in the area, being the initial articles Hofstede (1980) still very much quoted in various periodicals.

Using the existing cultural measures can understand how different variables (like the time perception, or universalism, particularism masculinity or femininity, hierarchical distance, need for uncertainty control) impact of form the decisive way to understand the concept in question.

From this perspective, most research in the area of applied social sciences, it is considered that the phenomena studied are essentially universal strong or strict, i.e. they are directly comparable between cultures and the differences found are in fact among the groups and not between the meaning of the concept or the use of the measuring instrument.

The context in which these instruments are created, many times, is closer to an individualistic culture, men with low hierarchical distance and with a low need for control of uncertainty, something close to the American results in studies of Hofstede (1991). In this sense, Karra and Phillips (2008) argue that one of the solutions to these problems by conducting research 
outside of your cultural context, as well as for the use of researchers belonging to the cultures studied.

In this situation, there is a greater ease of access to the data, reduced need for resources, smaller problems with translations and greater trust and relationship with the subjects of the research. The validity of the search should be established through the use of these researchers, so that they can determine the applicability of the construct measured

In addition, the statistical tests more rigorous. Currently much of the work in the area of Administration simply perform the verification of the data fit a tested structure, usually accomplished through a Confirmatory factor analysis, and the adequacy of reliability indices as Cronbach's alpha. While important, these tests are not enough, when is the comparison between groups, or validation of an instrument created in another culture.

It is necessary to establish the configural invariance, scale and metric equivalence, so that it can be considered that the scale measures the construct in the same way in different cultures or groups. These tests are typically implemented through verification procedures of gender parameters to determine if there is equivalence and how this equivalence (configural, metric or strict), inserting a constraint of equality of parameters between the groups, and observing the fit of the model. If the model continues with satisfactory adjustment, can perform comparisons between groups, so valid, because the instrument features equivalence in different cultures.

\section{Conclusions}

Although it is not viable, and even desirable, building theoretical models or instruments for each cultural context, must recognize the limitation of any instrument when used in another context, even passing by other criteria of validity Science, this validation is performed using statistical methods or not. Such limitation becomes even greater when growing differences between the culture where the instrument was created and where it is being applied.

However, the measure equivalence tests are not yet commonly employed when comparisons between different groups. Specifically in the area of applied social sciences (perhaps except for the area of Psychology), rare studies carry out tests of reliability beyond traditional single dimensionality testing (Cronbach's alpha), assuming that the concepts are understood similarly, by different groups, leaving much to be desired in terms of methodology.

The studies using scales and do not carry out these tests are likely to be making meaningless comparisons, theoretical because the scales may not measure the same constructs, or also present systematic differences in the way of answer the instrument, which represent different ways of completing the instrument, and not necessarily a difference in latent constructs measured by setting a serious threat to the validity of the study.

One way to ensure the validity of comparative studies, is the testing of equivalence or instrument of measurement invariance in the cultures studied. Ideally an instrument presents equivalent properties, this is the same structure and the same measure enabling the comparison and correct interpretation of the results obtained through the application of instruments in different groups.

Considering the difficulties and limitations of instruments used, also consider the use of alternative research methodologies, not only quantitative, but also the adoption of qualitative methods, longitudinal studies and to even other forms of investigation that make more sense for the population under study, including whenever possible, local interests in the definition of research (WESTWOOD; JACK, 2007). 
In a complex process of cross-cultural comparison, you can check which constructs like good and evil, justice, commitment, loyalty and ethics are not absolute concepts, depending on how each culture understands what is desirable and what is unacceptable in terms of the behavior of its members. It is recommended, therefore, that such differences are considered in the analysis and the use of the search results.

Research contributions, we can say that this article consolidates previous literature on the influence of the ' culture ' in the development of scientific research and the limitations on the use of instruments without proper validation, and establish the equivalence of constructs between the groups. In this sense, the efficient use of a scientific model requires, necessarily, your fitness to the specificities of the local context and exhaustive validation of its premises, as well as your application carefully and rigorously, as the use of procedures and appropriate methodologies.

Finally, this study drew attention to the fact that the constructs studied in research in the social sciences are not always absolute and universal, that is, the same suffering local cultural influences, these effects must be estimated, before If you perform comparisons between these groups.

\section{References}

BASKERVILLE.R.F. Hofstede Never Studied Culture. Accounting, Organizations and Society, 28, 1, January 2003, Pages 1-14, 2003.

BERRY, J.W, POORTINGA, Y.H ; SEGALL, M.H.; DASEN, P.R (2002) Cross-Cultural Psychology Research and Applications. Cambridge University Press: New York.

CARDOSO, R. L.; MEDONÇA NETO, O. R.; RICCIO E. L.; SAKATA, M. C. G. Pesquisa Científica em Contabilidade entre 1990 a 2003. Revista de Administração de Empresas (RAE). V 43. Junho, 2005.

CONTRACTOR, F.J. The raisons d'être for international management as a field of study. Journal of International Management, 6, p. 3-10, 2000.

CRESWELL, J. W. Qualitative inquiry and research design: choosing among five traditions. Thousand Oaks: Sage, 1998.

EMBER, C.R.EMBER, M. Cross-cultural research methods. Lanham: Altamira Press, 2009.

FRIEDLMEIER, W ; CHAKKARATH,P. ; SCHWARZ, B . Culture and human development:The importance of cross-cultural research to the social sciences.Lisse, The Netherlands: Swets \& Zeitlinger, 2005.

GEERTZ, C.. A Interpretação das Culturas. Rio de Janeiro, Zahar, 1973.

GODOY, Arilda Schmidt. Introdução a pesquisa qualitativa e suas possibilidades. Revista de Administração de Empresas, São Paulo, SP , v.35, n.2 , p.57-63, mar./abr. 1995 (a).

GOODENOUGH, W. H. "Culture" Encyclopedia of Cultural Anthropology. New York: Henry Holt, 1996.

HAIR, J. F.; TATHAM, R. L.; ANDERSON, R. E.; BLACK, W. Análise Multivariada de Dados. Porto Alegre: Bookman, 2005.

HILAL, A.V.G. Dimensões e Clusters de Cultura Organizacional de uma empresa brasileira com atuação internacional. Tese (Doutorado em Administração) Universidade Federal do Rio de Janeiro. 2001.

http://dx.doi.org/10.19085/journal.sijmas050401 
HOFSTEDE, G. Culture's consequences: international differences in work-related values. Beverly Hills, London: Sage Publications. 1980

HOFSTEDE,G. Culturas e Organizações: Como compreender a nossa programação mental Edições Síbalo Lda, 1a edição Lisboa. 1991.

HOUSE, R, M. JAVIDAN, HANGES, P., DORFMAN, P. (2002) Understanding Cultures and implicit theories across the Globe: an introduction to the Project GLOBE, Journal of World Business, 37, 2002. pp 3-10

HUI, C. H. TRIANDIS, H. C. Measurement in cross-cultural psychology: A review and comparison of strategies. Journal of Cross-Cultural Psychology, 16,131-152. 1985.

JACK, G.; CALÁS, M.; NKOMO, S. \& PELTONEN, T. Critique and International Management: an uneasy relationship? Academy of Management Special Issue ,33, 4, Oct. 2008.

KARRA, N.; PHILLIPS, N. Researching "Back Home": International Management Research as Autoethnography. OrganizationalResearch Methods, Vol. 11, No. 3, 541-561, 2008.

LINCOLN, Y., \& GUBA, E. G. (2000). Paradigmatic controversies, contradictions, and emerging conflicts. In N. K. Denzin \& Y. Lincoln (Eds.), Handbook of qualitative research (2nd ed., pp. 163-88). Thousand Oaks, CA: Sage.

LINTON, R. (1945). The cultural background of personality. New York: AppletonCentury Crofts.

MARCZYK, G., DEMATTEO, D., \& FESTINGER, D. (2005) Essentials of Research Design and Methodology. John Wiley \& Sons: Hoboken, New Jersey.

MARTINEZ, Z. \& TOYNE, B. What is international management and what is its domain? Journal of International Management, 6, p.11-28, 2000.

MORGAN, G. Imagens da Organização. São Paulo: Atlas, 1989.

NAKANE, C. Japonese Society. 1997

PUNNETT, B.J. (1998) 'Culture, Cross-national', inR.L. Tung (ed.) The International Encyclopedia of Business Management (IEBM). Handbook of International Business, pp. 51-67. London: International Thomson Business Press.

ROCHA, A. Empresas e Clientes: um Ensaio sobre Valores e Relacionamentos no Brasil. Rio de Janeiro 2004.

ROKEACH, M. The nature of human values. New York: The free press, 1973.

SEVERINO, A. J. Metodologia do trabalho científico. 22. ed. São Paulo: Cortez, 2002.

TRIANDIS, H. Some universals of social behavior. Personality and Social Psychology Bulletin, 1978,4, 1-16.

TROMPENAARS,F. Nas ondas da cultura. Como entender a diversidade cultural nos negócios. Educator - Editora: São Paulo, 1993. 
VAN DE VIJVER, F. J. R., \& POORTINGA, Y. H. (1982). Cross-cultural generalization and universality. Journal of Cross-Cultural psychology, 13, 387-408.

VERGARA, S. Projetos e relatórios de pesquisa em Administração. 8. ed. São Paulo: Atlas, 2007.

VERNON, R. In: Robock, S.H., Nehrt, L.C. (Eds.), Education in international business. Graduate School of Business, Indiana University, Bloomington, IN, pp. 7-10, 1964.

WESTWOOD, R. \& JACK, G. Manifesto for a post-colonial international business and management studies - A provocation. Critical Perspectives on International Business, 3, 3: p. 246-265. 